\title{
Applying Culturally Responsive Pedagogy to the Vocational Training of Immigrants
}

\author{
Ya-Ling Wu \\ Correspondence: Ya-Ling $\mathrm{Wu}$, Graduate Institute of Technological and Vocational Education, National Pingtung \\ University of Science \& Technology, Pingtung, Taiwan
}

Received: October 26, 2015 Accepted: November 12, 2015 Online Published: December 4, 2015

doi:10.11114/jets.v4i2.1165

URL: http://dx.doi.org/10.11114/jets.v4i2.1165

\begin{abstract}
Training and learning are the personal process in which individuals interact with social and cultural contexts. Immigrant trainees bring their early educational and life experiences into training classrooms, and their learning is strongly affected by their prior socialization and socio-cultural experiences. Therefore, it is necessary to provide immigrant trainees with vocational training programs in culturally responsive ways. That being said, the aim of this paper is to address the principles of culturally responsive pedagogy in adult education and their implications for vocational training of immigrants. The main implications of culturally responsive pedagogy in adult education for vocational training of immigrants are that vocational training instructors should have cultural self-awareness and reflection on their training practices as well as design and implement the culturally relevant vocational training programs, including integrating vocational training courses with knowledge and skills of immigrant trainees, affirming the cultural differences of immigrant trainees, developing learning communities, taking into account prior educational and work experiences of immigrant trainees, and utilizing multiple training methods and activities.
\end{abstract}

Keywords: culturally responsive pedagogy, vocational training, immigrant

\section{Introduction}

Transnational marriage reflects the phenomenon of globalization, and is the symbol of cultural integration, as well as the battlefield of cultural conflict. Asia is the place where the proportion of transnational marriage has been increasing steadily, and the proportion of transnational marriage in Taiwan is in first place among countries in Asia (The Economist, 2011). In Taiwan, most of the husbands of female immigrants are economically disadvantaged (Ministry of Interior, 2011), and these immigrant women are usually from less economically developed countries (Bélanger, Lee, \& Wang, 2010). Therefore, pursuing employment has become the most urgent need of female immigrants in Taiwan in order to support the economy of both natal and immediate families (Wu, 2013). Due to the lack of marketable human capital in host countries, most of female immigrants have to participate in vocational training programs to obtain employment. For female immigrants, acquiring vocational training in host countries is beneficial for their upward social mobility, improvement of economic independence, and their social and economic integration with host countries (Cohen \& Eckstein, 2010; Ghosh, 2001; Kogan, 2010). Therefore, encouraging immigrants to participate in vocational training programs has become one of important vocational training policies of receiving countries (Park, 2011).

In Taiwan, substantial resources have been invested in the vocational training of cross-border marriage immigrant women as a solution to their needs for employment. However, these vocational training programs especially for immigrant women are implemented in the Taiwanese-centric way without integrating the special socio-cultural experiences of these immigrant women trainees, which hinder their full participation in the training and negatively affect their training effectiveness. Consequently, female immigrants' participation rates in vocational training programs are usually low and dropout rates are high. The main reasons for the problems are that female immigrants attend Taiwanese-centered vocational training courses, and that vocational training instructors do not understand the cultural background and life experiences of female immigrants $(\mathrm{Wu}, 2013)$. The training courses and textbooks are not integrated with social and cultural experiences of female immigrants, and the content and methods of vocational training programs specifically designed for female immigrants are similar to those for general Taiwanese trainees (Chen $\& \mathrm{Gao}, 2010 ; \mathrm{Wu}, 2013)$. As a matter of fact, training effectiveness cannot be improved unless vocational training programs take into account the social and cultural contexts of trainees with multicultural background (Alfred, 2009). 
Although many scholars promote culturally responsive pedagogy in adult education (e.g., Alfred, 2002; Lee \& Sheared, 2002; Merriam, Caffarella, \& Baumgartner, 2007), it has only been implemented in a part of adult basic education and adult higher education. There is still a lack of studies investigating vocational training integrated with culturally responsive pedagogy for adult trainees with diversified social and cultural experiences. Therefore, the purpose of this paper is to address culturally responsive pedagogy and furthermore apply it to vocational training of immigrants.

\section{Culturally Responsive Pedagogy}

Culturally responsive pedagogy is an educational approach that suggests that curriculum, teaching, and interpersonal interactions in the educational process should be able to respond to the social and cultural contexts of learners and connect learners' cultural background and life experience with the learning they are now receiving. The learning effectiveness of learners could be improved in these ways (Banks, 2007). In learning sites, in order to help learners with cultural difference achieve great educational effectiveness, teachers should be able to understand learners' socio-cultural experiences, take into account their cultural background, learning patterns, communication styles, and use learners' prior experience as the bridge of learning (Banks, 2007; Gay, 2000). In terms of philosophy, culturally responsive pedagogy roots in the concepts of social justice, equity, and affirming human difference. Its ultimate objective is to empower learners and facilitate the fulfillment of social justice and equal opportunity (Banks, 2007). The important principles of culturally responsive pedagogy in adult education are presented as below.

\subsection{Adult Learning is Strongly Affected by adult Learners' Social and Cultural Contexts}

Vocational training is part of adult education. The objective of adult education is to adjust social injustice, as well as to empower all the disadvantaged adult learners (Johnson-Bailey \& Cervero, 2000). In fact, social and cultural factors play important roles in adult learning process (Merriam et al., 2007) and adult learning is strongly affected by all social, cultural, structural, and personal factors (Wertch, 1991), and is mediated by symbolic systems, such as language. Besides, the interaction among the factors is essential to learning (John-Steiner \& Mahn, 1996). The social approach emphasizes that interpersonal interactions and learning community have a significant influence on learning of adult learners. The cultural dimension of learning suggests that adult learning is closely related to learners' contexts, and that adult learners' interactions with contexts also affect their learning. Contexts include physical space, structure, and systems and culture with abundant historical meanings. Personal factors, such as gender, ethnic group, social class, and previous socialization experiences, all will affect the learning content and learning ways of adult learners (Alfred, 2003; Caffarella \& Merriam, 2000; Rogoff, 1995). Moreover, adult learners all are members of specific cultures who enter learning environment with their unique social and cultural experiences. Therefore, when adults engage in learning, they will develop personal learning based on the known in learning contexts (Alfred, 2009).

If learning environment is incompatible with the culture and life experiences of adult learners, learning gap will be generated to further make adult learners experience learning failure and even terminate their learning (Alfred, 2009). Therefore, it is indeed necessary to take into account social and cultural experiences of adult learners and provide them with culturally relevant adult education in their learning process.

\subsection{The Consistency between Cultures of Learning Sites and Cultural Background of Adult Learners Affects Learning Effectiveness}

Culture is the core of various types of education. Culture determines peoples' thinking and behaviors, and further affects people's teaching and learning (Trueba, 1988). Adult learners are different from traditional learners because they enter educational sites with abundant life and work experiences, as well as fixed learning patterns and significant cultural background. Therefore, teachers have to better understand the background of adult learners, as well as the influence of background on their adult education (Guy, 2002).

Learning sites cannot be fully consistent with culture of learners from different populations. However, such cultural discontinuity affects learners' learning achievements. Therefore, teachers have to understand the differences between learning sites and learners' culture in order to decrease conflicts, and reduce the gap among different cultures. If the transmitting ways of education can match learners' diversified cultural frameworks, learning performance of adult learners of minority groups could be improved (Alfred, 2002). Therefore, culturally responsive pedagogy affirms and uses adult learners' culture, history, and identity to design and implement curriculum and teaching (Alfred, 2003; Gay, 2000).

\subsection{Culturally Responsive Pedagogy Affirms Adult Learners' Social and Cultural Experiences}

Culturally responsive pedagogy utilizes the cultural knowledge, prior experiences, reference frameworks and performance patterns of adult learners, and then better connects adult learners' learning with their lives in order to improve their learning effectiveness. Culturally responsive pedagogy uses the advantages of adult learners to teach and train them and then in turn improve their advantages (Lee \& Sheared, 2002). As a result, culturally responsive adult 
education affirms the cultural and social experiences of adult learners. The characteristics of this principle are as follows (Guy, 2002; Wlodkowski, 1999): (1) to respect and cherish social and cultural experiences of different populations and group, as well as their influence on learning attitudes and ways of learners; (2) to build a meaningful bridge connecting learning sites with learners' prior experiences; (3) to use various teaching strategies to respond to the learning patterns of different learners; (4) to guide learners to understand and cherish their social and cultural experiences mutually.

\subsection{Culturally Responsive Pedagogy Encourages Mutual Cooperation of Learners}

Cooperation, communities and connection are core characteristics of culturally responsive pedagogy. Culturally responsive pedagogy encourages adult learners to cooperate with one another and be responsible for peers' learning. The mutual dependence, reciprocity, and assistance among learners are the guidelines of teachers' instruction instead of competition and individualism emphasized in traditional education. One of the objectives of culturally responsive pedagogy is to enable all the learners to become winners and to view assisting others in learning as their own responsibility (Banks, 2007).

In sum, culturally responsive pedagogy affirms, improves, and empowers adult learners of diversified backgrounds, as well as cultivates their cultural identity, learning performance, and personal abilities.

\section{Applying Culturally Responsive Pedagogy to Vocational Training of Immigrants}

The application of principles of culturally responsive pedagogy to vocational training of immigrants is addressed in the following two aspects: vocational training instructors' self-awareness and reflection on their training practices as well as design and implementation of culturally responsive vocational training.

\subsection{Vocational Training Instructors' Cultural Self-awareness and Reflection on Their Training Practices}

Vocational training instructors' multicultural attitudes can make immigrant learners' learning experiences more meaningful. Moreover, instructors can also create culturally relevant learning environment. Therefore, the development of culturally responsive vocational training programs originates from instructors' self-awareness and reflection on training practices (Guy, 1999; Alfred, 2002; Lee \& Sheared, 2002).

Firstly, training instructors have to examine their cultural assumptions of immigrants and understand how these assumptions affect their personal values, behaviors, and teaching. Because instructors' values affect their relationship with learners, they have to understand their personal negative perception of any culture, language or ethnic group (Lee \& Sheard, 2002; Richards, Brown \& Forde, 2006). Secondly, instructors have to reflect on the value and importance of vocational training for immigrants, understand the cultural and social experiences of immigrant trainees, and treasure their cultural diversity. These are extremely important to the improvement of instructors' multicultural literacy of $i$ managing and building culturally inclusive learning environment. Thirdly, instructors also have to continually engage in reflecting on and developing multicultural capabilities, and take actions to adjust personal ideology and teaching practices (Alfred, 2009; Lee \& Sheared, 2002).

\subsection{Design and Implementation of Culturally Responsive Training}

Culturally responsive pedagogy requests training instructors to pay attention to the design and implementation of instruction during the vocational training process. Culturally responsive pedagogy addresses the needs of all the learners. Therefore, adequate vocational training curriculum and training strategies become and the bridges connecting immigrant trainees with local trainees. In this way, it can create culturally responsive training environment which makes the cultural and social experiences of all the trainees visible and affirmed in the classroom (Richards, et al., 2006).

\subsubsection{Integrating Vocational Training Courses with Knowledge and Skills of Immigrant Trainees}

During the design of vocational training curriculum, the integration with knowledge and skills of other countries or cultures is beneficial to the preservation of immigrant trainees' prior knowledge and abilities. Instructors have to endeavor to reduce the gap in knowledge and skills between immigrant trainees and native trainees. Vocational training integrated with knowledge and skills of immigrant trainees can improve all the trainees' cross-cultural literacy, as well as enhance the levels of cultural responsiveness and relevance of vocational training programs. Culturally responsive training could create equal training opportunities, enable all trainees to experience their past life experiences and culture in the classroom and then to improve their learning continuity, as well as help trainees acculturate in the new environments (Guy, 1999). Therefore, instructors have to be familiar with knowledge and skill background of immigrant trainees.

\subsubsection{Affirming the Cultural Differences of Immigrant Trainees}

It is import for instructors to perceive the mutually shared values and culture of trainees. However, it is also essential for them to understand their individual difference. Therefore, instructors have to take into account the personal traits of 
immigrant trainees. Instructors could provide trainees with opportunities to share their life and cultural experiences. In this way, both instructors and trainees can better understand and treasure one another in the aspect of globalization. In addition, cooperation enables trainees to become closely related to one another, reduce the power relationship between immigrant trainees and native trainees, and shorten the cultural distance in the classroom (Alfred, 2003; Neito, 2000).

\subsubsection{Developing Learning Communities}

Instructors should design training activities that can improve trainees' relationships because community activities in class are beneficial to the social support network of trainees of different populations and could reduce immigrant trainees' anxiety about new environment. The strategies of helping immigrant trainees involve in the class are as follows: encouraging trainees to participate in formal or informal team activities, and developing learning partners and learning groups, etc. These group interactions are beneficial to the socialization and knowledge sharing of immigrant trainees (Merriam \& Kim, 2008).

\subsubsection{Taking into Account Prior Educational and Work Experiences of Immigrant Trainees}

Prior educational and work experiences are the differences between adult immigrant learners and children or teenager learners. Therefore, immigrant trainees bring their life stories into the classroom of vocational training. Hence, culturally responsive pedagogy emphasizes that vocational training programs should integrate immigrant trainees' abundant knowledge as well as educational and work experiences into programs as the foundation of subsequent learning (Merriam \& Kim, 2008).

\subsubsection{Utilizing Multiple Training Methods and Activities}

Learning patterns preferred by immigrant trainees from different cultural groups are diversified. Therefore, instructors have to implement all kinds of training activities, including group activities and individual practices, to meet the needs of immigrant trainees of different learning patterns (Caffarella \& Merriam, 2000).

With continuous application of the principles or strategies of culturally responsive pedagogy mentioned above, instructors of vocational training could start to gradually transform vocational training class into culturally relevant learning environment. In this way, immigrant trainees could fully participate in vocational training programs.

\section{Conclusion}

Training and learning are the personal process in which individuals interact with social and cultural environmental contexts. Each immigrant trainee enters vocational training fields with his/her abundant socio-cultural experience, and his/her vocational training is strongly affected by prior socialization and socio-cultural experiences (Alfred, 2009). Therefore, vocational training organizations should provide vocational training programs in a culturally-meaningful way to meet the diversified needs of immigrant trainees, improve their training effectiveness, and further to empower them.

\section{References}

Alfred, M. (2002). The promise of sociocultural theory in democratizing adult education. In Alfred, M. (Ed.). Learning and sociocultural contexts. New Directions for Adult and Continuing Education, 96, 3-14. http://dx.doi.org/10.1002/ace.74

Alfred, M. V. (2003). Sociocultural contexts and learning: Anglophones Caribbean immigrant women in U. S. postsecondary education. Adult Education Quarterly, 53(4), 242-260. http://dx.doi.org/10.1177/0741713603254028

Alfred, M. V. (2009). Nonwestern immigrants in continuing higher education: A sociocultural approach to culturally responsive pedagogy. Journal of Continuing Higher Education, 57(3), 137-148. http://dx.doi.org/10.1080/07377360903262168

Banks, J. A. (2007). Approaches to Multicultural Curriculum Reform. In J. A. Banks \& C. A. Banks(Eds.), Multicultural education: Issues and perspectives( $6^{\text {th }}$ ed) (pp.247-270). Boston: Allyn and Bacon.

Bélanger, D. L., Lee, H. K., \& Wang, H. Z. (2010). Ethnic diversity and statistics in East Asia: 'Foreign brides' surveys in Taiwan and South Korea. Ethnic and Racial Studies, 33(6), 1108-1130. http://dx.doi.org/10.1080/01419870903427507

Caffarella, R., \& Merriam, S. B. (2000). Linking the individual learner to the context of adult learning. In A, L. Wilson \& E. R. Hayes (Eds.), Handbook of adult and continuing education (pp.55-70). San Francisco, CA: Jossey-Bass.

Chen, Z. U., \& Gao, H, M. (2010). Evaluation of the effectiveness of vocational training among foreign spouses. Taipei, Taiwan: Interior of Ministry. 
Cohen-Goldner, S., \& Eckstein, Z. (2010). Estimating the return to training and occupational experience: The case of female immigrants? Journal of Econometrics, 156, 86-105. http://dx.doi.org/10.1016/j.jeconom.2009.09.009

Gay, G. (2000). Culturally responsive teaching: Theory, research, and practice. New York: Teachers College Press.

Ghosh, R. (2001). Identity and integration: Girls from a minority ethno-cultural group in Canada. McGill Journal of Education, 35(3), 279-296.

Guy, T. C. (1999). Culture as context for adult education: The need for culturally relevant adult education. In T. C. Guy (Ed.), Providing culturally relevant adult education: A challenge for the twenty-first century. New Directions for Adult and Continuing Education, No. 82 (pp. 5-18). San Francisco, CA: Jossey-Bass. http://dx.doi.org/10.1002/ace.8201

Guy, T. C. (2002). Black immigrants of the Caribbean: An invisible and foreign community. Adult learning, 12(4), $18-21$.

Johnson, B., \& Cervero, R. M. (2000). The invisible politics of race in adult education. In A. L. Wilson \& E. R. Hayes (Eds.). Handbook of Adult and Continuing Education (pp.147-160).

John-Steiner, V., \& Mahn, H. (1996). Sociocultural approaches to learning and development: A Vygotskian framework. Educational Psychologist, 31, 191-206. http://dx.doi.org/10.1080/00461520.1996.9653266

Kogan, I. (2010). Immigrant investment in host country vocational education and training. International encyclopedia of education, 2010, 280-288. http://dx.doi.org/10.1016/B978-0-08-044894-7.00769-7

Lee, M., \& Sheared, V. (2002). Socialization and immigrant students' learning in adult education programs. In Alfred, M. (Ed.), Learning and sociocultural contexts. New Directions for Adult and Continuing Education, 96, 27-36. http://dx.doi.org/10.1002/ace.76

Merriam, S. B., \& Kim, Y. S. (2008). Nonwestern perspectives on learning and knowing. In S. B. Merriam (Ed.), Third update on adult learning theory (pp. 71-81). New Directions for Adult and Continuing Education, No. 119. Maiden, MA: Wiley InterScience.

Merriam, S. B., Caffarella, R., \& Baumgartner, L. M. (2007). Learning in adulthood: A comprehensive guide. San Francisco, III: Jossey-Bass.

Minister of Interior (2011). Summary of the survey on the life conditions of foreign and Mainland Chinese spouses in 2011. Taipei, Taiwan: Minister of Interior.

Neito, S. (2000). Affirming diversity: The sociopolitical context of multicultural education. New York: Longman.

Park, J. (2011). Job-related training of immigrants-perspectives on labour and incomes. Canada: Statistics Canada. Retrieved from http://www5.statcan.gc.ca/bsolc/olc-cel/olc-cel?catno=75-001-X201100311539\&lang=eng

Richards, H. V., Brown, A., \& Forde, T. B. (2006). Addressing diversity in schools: Culturally responsive pedagogy. Tempe, AZ: Arizona State University, National Center for Culturally Responsive Educational Systems.

Rogoff, B. (1995). Observing sociocultural activity in three planes: Participatory appropriation guided participation, and apprenticeship. In J. V. Wertsch, Pablo del Rio, Amelia A. (Eds.), Sociocultural studies of the mind (pp.139-164). Cambridge, England: Cambridge University Press.

The Economist (2011). International marriage: Herr and Madame, Señor and Mrs. http://www.economist.com/node/21538103.

Trueba, H. (1988). Culturally-based explanations of minority students' academic achievement. Anthropology of Education Quarterly, 19(1), 270-297. http://dx.doi.org/10.1525/aeq.1988.19.3.05x1565e

Wertch, J. (1991). Voices and mind: A sociocultural approach to mediated action. Cambridge, Mass: Harvard University Press.

Wlodkowski, R. J. (1999). Enhancing adult motivation to learn: A Comprehensive guide for teaching all adults. San Francisco: Jossey-Bass.

Wu, Y. L. (2013). A Socio-cultural Approach to Understanding the Learning Experiences of Vocational Training among Vietnamese Immigrant Women in Taiwan. Women's Studies International Forum, 44, 80-88. http://dx.doi.org/10.1016/j.wsif.2013.10.004

This work is licensed under a Creative Commons Attribution 3.0 License. 